\title{
MEMBANGUN PERMAINAN EDUKASI ANDROID “FLORA THE EXLPORER” PENGENALAN TUMBUH-TUMBUHAN
}

\author{
Rahmad Rizky Fauzi' ${ }^{1)}$, Lilyana ${ }^{2)}$, dan Ahmad Fahrijal Pukeng ${ }^{3)}$ \\ 1,3,4 Teknik Informatika, STMIK Widya Cipta Dharma \\ ${ }^{2}$ Manajemen Informatika, STMIK Widya Cipta Dharma \\ $1,2,3$ Jl. M. Yamin No.25, Samarinda, 75123 \\ E-mail : rahmadrizky22@gmail.com ${ }^{1)}$, lilyana.ritter@gmail.com ${ }^{2)}$,rizalpukeng@gmail.com ${ }^{3)}$
}

\begin{abstract}
ABSTRAK
Permainan edukasi berbasis simulasi didesain untuk mensimulasikan permasalahan yang ada sehingga diperoleh ilmu yang dapat digunakan untuk menyelesaikan permasalahan tersebut. Permainan simulasi dengan tujuan edukasi ini dapat digunakan sebagai salah satu media edukasi yang memiliki pola pembelajaran learning by doing. Berdasarkan pola yang dimiliki oleh permainan tersebut, pemain dituntut untuk belajar sehingga dapat menyelesaikan permasalahan yang ada. Dalam pembuatan permainan edukasi android "Flora The Explorer pengenalan tumbuh-tumbuhan. Aplikasi yang digunakan dalam membuat permainan adalah Swish max4 dan dengan tahapan pengembangan multimedia, serta menerapkan algoritma shuffle random. Diharapkan permainan ini tidak menjadi monoton dan pemain tidak dapat mengingat posisi gelembung pada permainan dengan adanya algoritma shuffle random
\end{abstract}

Kata Kunci: Tumbuhan, Permainan Edukasi, Android, Shuffle Random, Multimedia

\section{PENDAHULUAN}

Permainan edukasi sangat menarik untuk dikembangkan. Ada beberapa kelebihan dari permainan edukasi dibandingkan dengan metode edukasi konvesional. Salah satu kelebihan utama permainan edukasi adalah visualisasi dari permasalahan nyata (De Freitas, 2018). Permainan edukasi berbasis simulasi didesain untuk mensimulasikan permasalahan yang ada sehingga diperoleh ilmu yang dapat digunakan untuk menyelesaikan permasalahan tersebut.

Kebanyakan permainan sekarang tidak mendidik anak (Elliani. 2014). Anak lebih senang menggunakan gadget untuk memainkan permainan dewasa seperti perang atau perkelahian. Oleh sebab itu dibutuhkan permainan yang bisa mengajak anak bermain sambil belajar. "Flora the Explorer" sebuah nama permainan yang akan dibangun dengan maksud mengenalkan dunia flora atau tumbuh-tumbuhan kepada anak. Dimana pemain harus belajar terlebih dahulu tentang dunia tumbuhan, barulah dapat menjawab tantangan dala permainan edukasi ini. Permainan ini mengajak pemain untuk menangkap sejumlah buah atau tanaman yang jatuh dari pohon.

Diperluka sebuah teknik untuk mengacak posisi jatuhnya buah-buahan tersebut, karena apabila tidak dilakukan pengacakan maka anak sebagai pemain dapat dengan mudah mengingat posisi jatuhnya buah-buahan tersebut, dan lama kelamaan permainan akan mudah membuat bosan (Budiarso \& Nurraharjo, 2018)

Untuk itu dalam penelitian membangun permainan edukasi android "Flora The Explorer" untuk pembelajaran mengenal jenis-jenis dan manfaat tumbuhan ini, penelitian menggunakan algoritma pengacakan posisi (shuffle random) agar permainan tidak monoton, dan tidak mudah untuk ditebak tentang soal yang akan diberikan nantinya.

\section{RUANG LINGKUP PENELITIAN}

Permasalahan difokuskan pada :

1. Permainan edukasi diperuntukkan untuk anak usia dini (3-6) tahun.

2. Permainan edukasi ini belajar dan bermain tentang nama dan ejaan tumbuhan.

3. Permainan edukasi ini memiliki permainan yang terdiri dari 10 level.

4. Permainan edukasi ini mengenalkan 2 kategori tumbuhan dengan 10 jenis tumbuhan pada masingmasing kategori.

5. Pembuatan permainan menggunakan SwishMax4.

6. Algoritma yang digunakan pada permainan ini yaitu algoritma logika pengacakan posisi objek (shuffle random) yang berfungsi untuk mengacak soal atau objek

\section{BAHAN DAN METODE}

Adapun bahan dan metode yang gunakan dalam membangun permainan ini yaitu:

\subsection{Permainan Edukasi}

Menurut Ismail (2009), permainan merupakan salah satu multimedia yang banyak digemari oleh masyarakat. permainan dimainkan oleh semua kalangan, dari usia remaja hingga dewasa. permainan mempunyai peranan penting bagi perkembangan teknologi manusia. Dari segi tampilan, musik dan penerapan hiburan yang populer 
untuk semua kalangan usia. Sejak pertama kali ditemukan sampai saat sekarang, permainan telah mengalami kemajuan yang terbilang pesat dalam bidang teknologi. Sedangkan Game Edukasi adalah salah satu jenis media yang digunakan dalam memberikan pengajaran yang berupa permainan dengan tujuan untuk merangsang daya pikir dan meningkatkan konsentrasi melalui media yang unik dan menarik (Setiawati, 2008).

\subsection{Algoritma Pengacakan Posisi}

Menurut Andrea (2013), Shuffle random adalah pengacakan urutan indeks dari sebuah record atau array. Pengacakan ini diibaratkan pengocokan pada dek kartu, dimana semua kartu dikocok sehingga susunannya teracak. Contoh lain misalkan A adalah array $5 \times 1, \mathrm{~A}=$ [ $\left.\begin{array}{lllll}1 & 2 & 3 & 4 & 5\end{array}\right]$ maka proses shuffle random akan mengacak susunan indek dari array A menjadi A1 $=\left[\begin{array}{lllll}5 & 1 & 3 & 2 & 4\end{array}\right]$ ataupun menjadi susunan array yang lain. Dalam bahasa pemrograman fungsi shuffle random tidak hanya dapat mengacak angka, tetapi juga dapat mengacak array string ataupun campuran string dan angka.

\subsection{Android}

Menurut Safaat (2012), Android merupakan subset perangkat lunak untuk perangkat mobile yang meliputi sistem operasi, middleware dan aplikasi inti yang direlease oleh Google. Sedangkan Android SDK (Software Development Kit) menyediakan Tools dan API (Aplication Programing Interface) yang diperlukan untuk mengembangkan aplikasi pada platform Android dengan menggunakan bahasa pemrograman Java. Dikembangkan bersama antara Google, HTC, Intel, Motorola, Qualcomm, T-Mobile, NVIDIA yang tergabung dalam OHA (Open Handset Alliance) dengan tujuan membuat sebuah standar terbuka untuk perangkat bergerak (mobile device).

\subsection{SwishMax4}

SwishMax4 merupakan pengembangan dari Program Swish v.3, yang kini telah memiliki 230 bulit-in efek seperti efek Explode, Vortex, 3D Spin, Snake dan banyak lainnya. Seperti halnya Swish, SwishMax juga memilki alat bantu untuk membuat garis, kotak, elips, kurva bazier, gerak animasi, sprite, tombol roll over dan lainnya. Format dasar SwishMax adalah swi file, namun dapat juga diekspor kedalam file flash (swf), movie (avi) ataupun execute (exe) program yang dapat dijalankan berdiri sendiri. Sehingga animasi Swishmax dapat diletakkan langsung di web, atapun diikutkan dalam presentasi Microsoft Powerpoint dan Microsoft Word (Adnyana, 2010).

\subsection{Tahapan Pengembangan Multimedia}

Menurut Binanto (2010), dapat dilihat pada gambar 1, metodologi pengembangan multimedia terdiri dari enam tahap, yaitu concept (pengonsepan), design (perancangan), meterial collecting (pengumpulan materi), assembly (pembuatan), testing (pengujian), dan distribution (pendistribusian). Keenam tahap ini tidak dapat bertukar posisi. Meskipun begitu, tahap concept memang harus menjadi hal yang pertama kali dikerjakan.

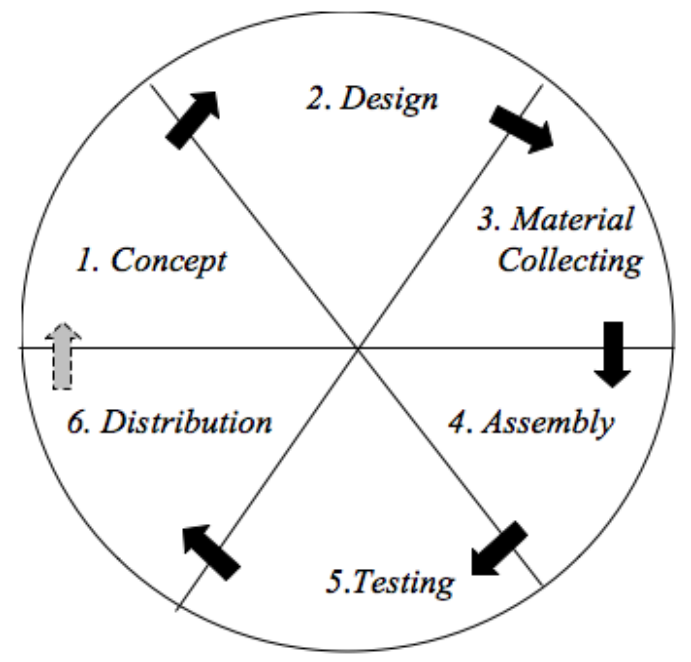

Gambar 1. Tahapan Pengembangan Multimedia

Tahapan pengembangan multimedia meliputi (Pressman, 2010) :

1. Concept

Concept (pengonsepan) adalah tahap untuk menentukan tujuan dan siapa pengguna program (identifikasi audiance). Tujuan dan penguna akhir program berpengaruh pada nuansa multimedia sebagai pencerminan dari indentitas organisasi yang menginginkan informasi sampai pada pengguna akhir. Karakteristik pengguna termasuk kemampuan pengguna juga perlu dipertimbangkan karena dapat memengaruhi pembuatan desain. Selain itu, tahap ini juga akan menentukan jenis aplikasi (presentasi, interaktif, dan lain-lain) dan tujuan aplikasi (hiburan, pelatihan, pembelajaran dan lain-lain). Dasar aturan untuk perancangan juga ditentukan pada tahap ini, misalnya ukuran aplikasi, target, dan lain-lain. Output dari tahap ini biasanya berupa dokumen yang bersifat naratif untuk mengungkapkan tujuan projek yang ingin dicapai.

2. Design

Design (perancangan) adalah tahap pembuatan spesifikasi mengenai arsitektur program, gaya, tampilan, dan kebutuhan material/bahan untuk program. Spesifikasi dibuat serinci mungkin sehingga pada tahap berikutnya, yaitu material collecting dan assembly, pengambil keputusan baru tidak diperlukan lagi, cukup menggunakan keputusan yang sudah ditentukan pada tahap ini. Meskipun demikian, pada prakteknya, pekerjaan proyek pada tahap awal masih akan sering mengalami penambahan bahan atau pengurangan bagian aplikasi, atau perubahanperubahan lain. 


\section{Material Collecting}

Material Collecting adalah tahap pengumpulan bahan yang sesuai dengan kebutuhan yang dikerjakan. Bahan-bahan tersebut, antara lain gambar clip art, foto, animasi, video, audio, dan lain-lain yang dapat diperoleh secara gratis atau dengan pemesanan kepada pihak lain sesuai dengan rancangannya. Tahap ini dapat dikerjakan secara paralel dengan tahap assembly. Namun, pada beberapa kasus, tahap material collecting dan tahap assembly akan dikerjakan secara linear dan tidak paralel.

4. Assembly

Assembly adalah tahap pembuatan semua objek atau bahan multimedia. Pembuatan aplikasi didasarkan pada tahap design, bagan alir, dan atau struktur navigasi.

5. Testing

Testing (pengujian) dilakukan setelah menyelesaikan tahap pembuatan (assembly) dengan menjalankan aplikasi/program dan melihatnya apakah ada kesalahan atau tidak. Tahap pertama pada tahap ini disebut tahap pengujian alpha (alpha test) yang pengujiannya dilakukan oleh pembuat atau lingkungan pembuatnya sendiri. Setelah lolos dari pengujian alpha, pengujian beta yang melibatkan penggunaan akhir akan di lakukan.

6. Distribution

Pada tahap ini, aplikasi akan disimpan dalam suatu media penyimpanan. Jika media penyimpanan tidak cukup untuk menampung aplikasinya, proses compress terhadap aplikasi tersebut akan dilakukan. Tahap ini juga dapat disebut tahap evaluasi untuk pengembangan produk yang sudah jadi supaya menjadi lebih baik. Hasil evaluasi ini dapat digunakan sebagai masukkan untuk tahap concept pada produk selajutnya.

\section{RANCANGAN APLIKASI}

Dalam konsep pembuatan permainan edukasi android "Flora The Explorer" semua konsep mulai dari perancangan permainan Flora The Explorer pengenalan nama tumbuhan Unified Modeling Language (UML). Terdapat 2 Activity Diagram dalam konsep game ini. Untuk mengenal proses dari suatu sistem digunakan diagram Activity Diagram. Dengan Activity Diagram ini dapat diketahui proses yang terjadi pada aplikasi (Nugroho, 2010).
1. Activity Diagram Belajar permainan edukasi android "Flora The Explorer".

Dapat dilihat pada gambar 2, Alur aktifitas yang terjadi disaat pemain memilih "Belajar" pada menu utama. Saat pemain memilih "Belajar", maka sistem akan langsung menampilkan scene "Belajar" dan memilih kategori materi yang ingin dipelajari. Setalah itu pemain dapat memulai belajar mengenal 10 nama tumbuhan.

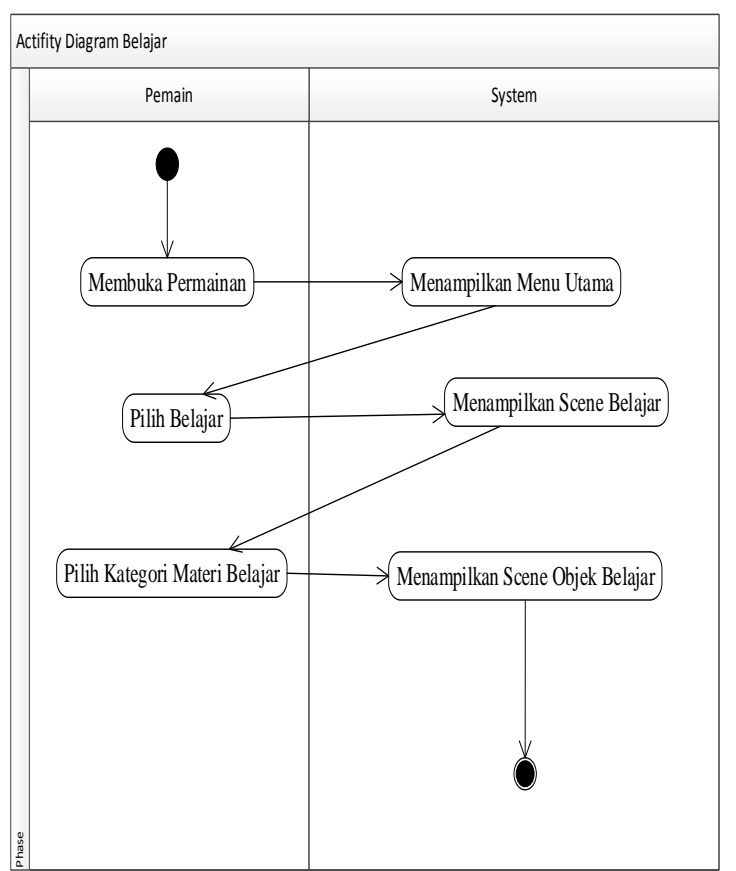

Gambar 2. Activity Diagram Belajar

2. Activity Diagram Bermain "Flora The Explorer"

Gambar 3 menunjukkan, alur aktifitas yang terjadi disaat pemain memilih "Bermain" pada menu utama. Saat pemain memilih "Bermain", sistem akan langsung menampilkan menu bermain, jika pemain memilih mulai bermain maka sistem akan menampilkan permainan level pertama. Jika pemain berhasil memenangkan permainan level pertama maka akan masuk pada scene berhasil dan mendapatkan 1 bintang tapi jika tidak berhasil akan masuk pada scene kalah dan tidak mendapatkan bintang. Jika pemain berhasil memenangkan permainan level pertama pemain bisa memilih lanjut pada level selanjutnya hingga level 10 dan menang dan mendapatkan 10 bintang, tetapi jika tidak berhasil memenangkan hingga level 10 makan pemain akan masuk pada scene kalah. 


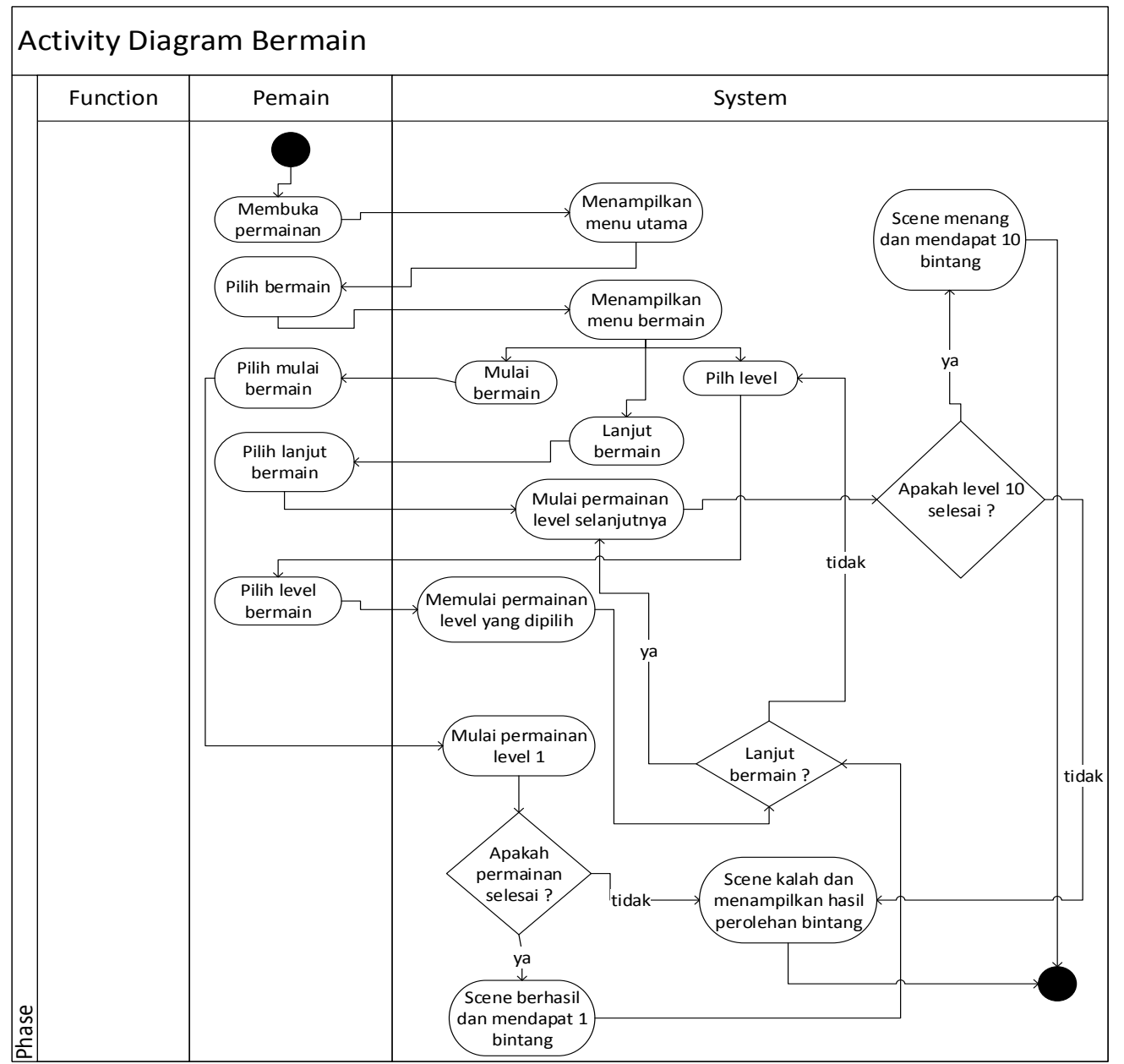

Gambar 3. Activity Diagram Bermain

\section{IMPLEMENTASI}

Hasil implementasi berdasarkan konsep dan perancangan adalah sebagai berikut:

1. Tampilan Menu Utama

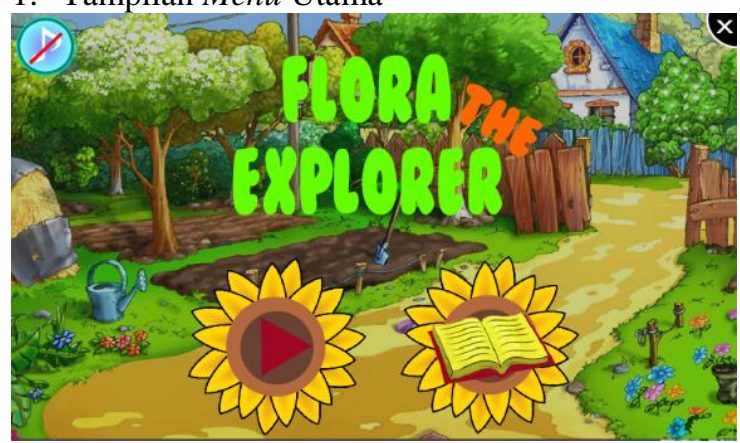

Gambar 4. Menu Utama

Seperti yang terlihat pada gambar 4, Terdapat nama atau judul dari permainan edukasi android "Flora The Explorer mengenal tumbuh-tumbuhan”. Setiap tombol pada scene menu utama memiliki fungsi masing-masing, saat kita mengklik button belajar maka akan ditampilkan scene belajar, saat kita mengklik button bermain maka akan ditampilkan scene bermain, saat kita mengklik tombol musik maka akan mengaktifkan/menonaktifkan musik pengiring permainan dan ketika kita mengklik button keluar maka permainan akan keluar dari aplikasi.

\section{Tampilan Scene Belajar}

Pada gambar 5 Scene Belajar adalah scene dimana pemain dapat memilih kategori materi belajar yang ingin dipelajari, sehingga memudahkan pemain dalam menyelesaikan misi yang di berikan pada scene bermain nantinya.

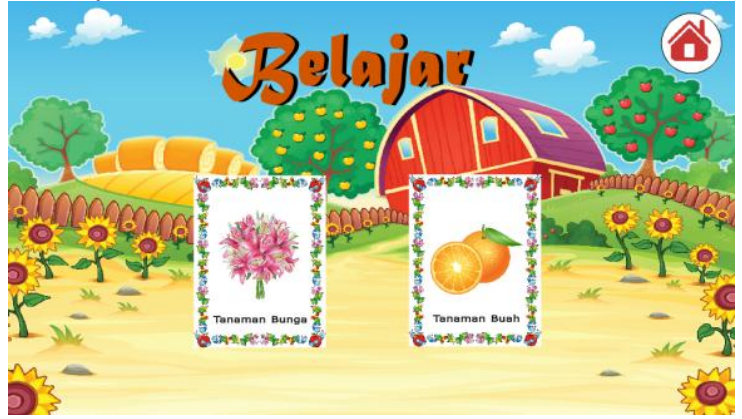

Gambar 5. Tampilan Belajar 
3. Tampilan Scene Mawar

Pada gambar 6 Scene Mawar adalah scene dimana pemain dapat mempelajari nama bunga mawar dan tumbuhan lainnya beserta ejaanya.

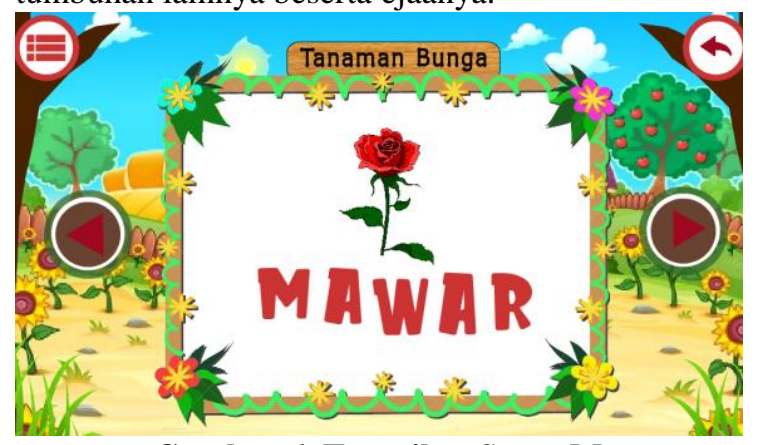

Gambar 6. Tampilan Scene Mawar

4. Tampilan Scene Bermain

Pada gambar 7 dan 8 Scene Bermain adalah scene dimana pemain bermain dengan cara menyelesaikan misi sesuai dengan pertanyaan sebelum waktu selesai, pemain harus menyelesaikan sepuluh level dengan ketentuan pemain tidak boleh gagal dalam menyelesaikan permainan pada setiap level, jika gagal maka pemain harus mengulang permainan dari level pertama.

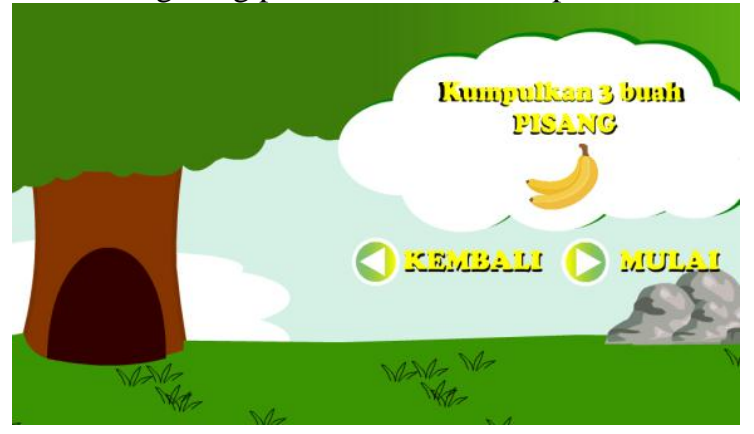

Gambar 7. Scene Misi

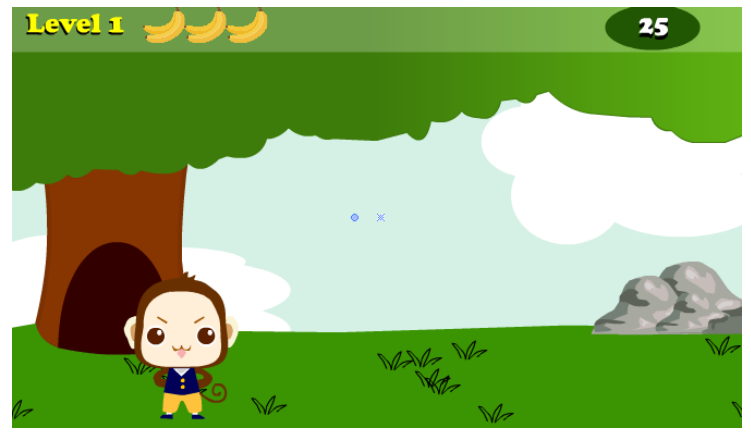

Gambar 8. Scene Permainan.

5. Tampilan Scene Level

Pada gambar 9 Scene Level adalah scene dimana pemain dapat memulai permainan dari level 1 atau memilih level jika permainan dilanjutkan.

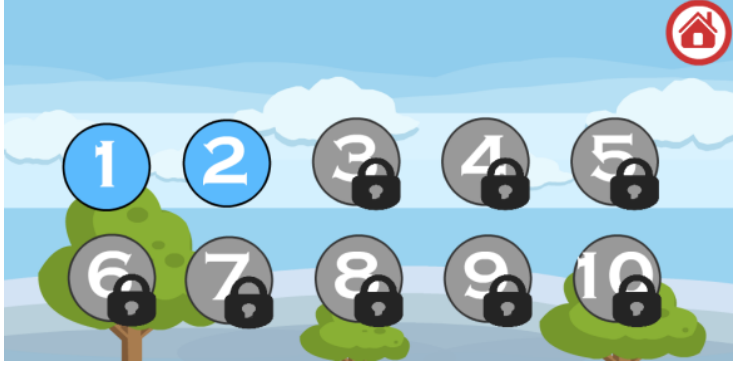

Gambar 9. Scene Level.

6. Tampilan Scene Misi Berhasil

Pada gambar 10 Scene Misi Berhasil adalah scene yang akan tampil jika pemain berhasil menyelesaikan misi pada satu level.

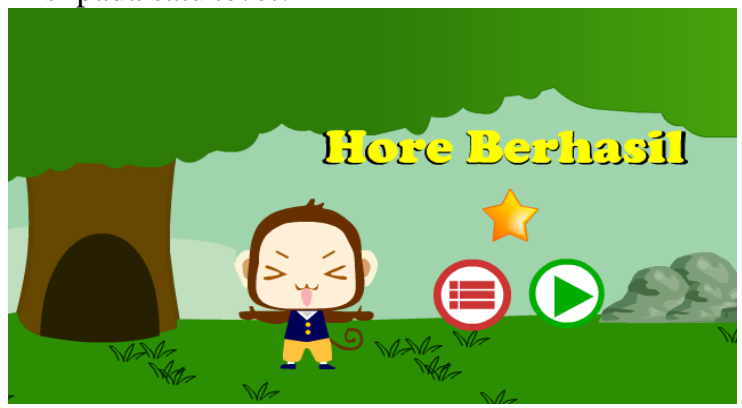

Gambar 10. Scene Misi Berhasil.

7. Tampilan Scene Gagal

Pada gambar 11 Scene gagal adalah scene yang akan menampilkan hasil akhir atau hasil dari level yang sudah terselesaikan.

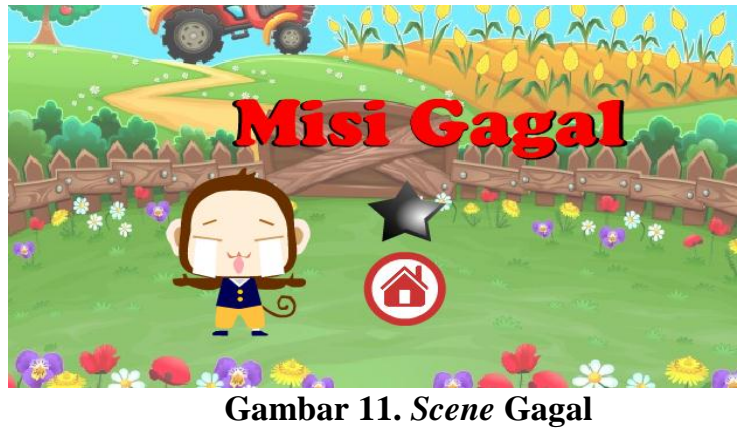

8. Tampilan Scene Menang

Pada gambar 12 Scene Menang adalah scene yang akan tampil jika pemain berhasil menyelesaikan semua level.

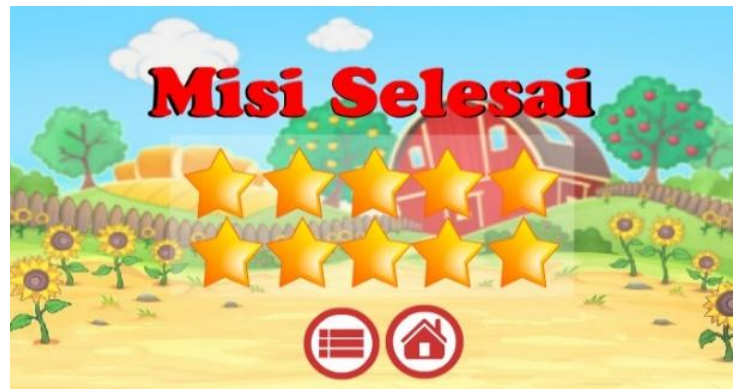

Gambar 12. Scene Menang 


\section{KESIMPULAN}

Berdasarkan uraian dari masing-masing bab dan hasil pembahasan maka dapat disimpulkan bahwa pembuatan permainan edukasi android "Flora The Explorer" pengenalan tumbuh-tumbuhan sebagai berikut :

1. Konsep permainan edukasi android "Flora The Explorer" pengenalan tumbuh-tumbuhan adalah permainan edukasi yang dapat membantu anak-anak mengenal nama-nama tumbuhan beserta ejaannya, sehingga dibuatlah permainan edukasi yang bersifat multimedia.

2. Permainan edukasi ini menggunakan algoritma pengacakan posisi objek permainan atau bisa disebut shuffle random yang berfungsi untuk mengacak objek dengan tujuan agar pemain tidak dapat mengingat letak objek dalam permainan.

\section{DAFTAR PUSTAKA}

Adnyana. M.A. 2011, Modul Swishmax. http : // ilmukomputer.org / 2008/11/ 25 /animasiflashdengan-swishmax-2/. diakses pada tanggal 8 September 2012.

Andrea, R. 2013, Teknik Pengacakan Posisi - Find Me The Game Prosiding Senaik. Samarinda : Unmul Press.

Binanto, I. 2010, Multimedia Digital-Dasar Teori dan Pengembangannya. Yogyakarta : Andi
Budiarso, Z., \& Nurraharjo, E. 2018. Implementasi Algoritma Random Pada Permainan Ketangkasan. Dinamik, 23(2), 97-100.

De Freitas, S. 2018. Are games effective learning tools? A review of educational games. Journal of Educational Technology \& Society, 21(2), 74-84.

Elliani. 2014, Membangun Game edukasi Smart\&Fun Hijaiyah Berbasis Android. Samarinda : STMIK Widya Cipta Dharma.

Ismail, A. 2009, Education Games. Jakarta : Proumedia.

Safaat, N. 2012, (Edisi Revisi). Pemograman Aplikasi Mobile Smartphone dan Tablet PC Berbasis Android. Informatika. Bandung.

Nugroho, A. 2010, Rekayasa Perangkat Lunak Berorientasi Objek dengan Metode USDP, Yogyakarta : Penerbit Andi Offset.

Pressman, R. 2010, Software Engineering: A Practitioner's Approach. McGraw-Hill.

Setiawati, 2008. Education Games. Jakarta : Proumedia.

UCAPAN TERIMA KASIH

Publikasi PKM-PE ini dibiaya oleh BELMAWA RISTEKDIKTI Tahun 2019 